\title{
Conflict of intentions due to callosal disconnection
}

T Nishikawa, J Okuda, I Mizuta, K Ohno, J Jamshidi, H Tokunaga, Y Ikejiri, Y Nakagawa, $\mathrm{T}$ Yoshimine, $\mathrm{H}$ Tanabe, $M$ Takeda

Department of Clinical Neuroscience Psychiatry, Osaka University Graduate School of Medicine, D3, 2-2 Yamadaoka, Suita City, Osaka

565-0871, Japan

T Nishikawa

I Mizuta

H Tokunaga

Y Ikejiri

Y Nakagawa

M Takeda

Department of Clinical Neuroscience

Neurosurgery, Osaka

University Graduate

School of Medicine,

Osaka, Japan

$\mathrm{T}$ Yoshimine

Department of

Psychiatry, Shoraiso

National Hospital,

Nara, Japan

J Okuda

Department of

Rehabilitation,

Hoshigaoka

Kosei-Nenkin

Hospital, Osaka, Japan

K Ohno

Department of

Neurosurgery, Settsu

Iseikai Hospital,

Osaka, Japan

J Jamshidi

Department of

Neuropsychiatry,

Ehime University

School of Medicine,

Ehime, Japan

$\mathrm{H}$ Tanabe

Correspondence to:

Dr T Nishikawa

nisikawa@

psy.med.osaka-u.ac.jp

Received 1 August 2000 and

in final form

1 May 2001

Accepted 10 May 2001
Abstract

Objectives-Three patients with callosal syndrome manifested a peculiar symptom in that they were unable to perform intended whole body actions because another intention emerged in competition with the original one. Attempts were made to clarify the symptomatology of this manifestation and its possible mechanism is discussed.

Methods-The three patients are described and previous reports on patients with callosal damage were reviewed. Four additional patients with similar symptoms were found and the clinical features common to all seven patients were examined. Results-This symptom could not be attributed to unilateral movement disorders such as unilateral apraxia, intermanual conflict, or compulsive manipulation of tools. The manifestations included marked hesitation in initiating actions, interruption of actions, repetitive actions, and performance of unintended actions with difficulty in correcting them. All patients, except one, had a lesion in the posterior half of the body of the corpus callosum, and there was no significant involvement of the cerebral cortex. The symptom became manifest later than 4 weeks after callosal damage. It occurred during spontaneous actions, but not during well automated actions nor when following instructions.

Conclusion-This symptom, tentatively named "conflict of intentions", can be regarded as a fragment of diagonistic dyspraxia originally described by Akelaitis, although it can occur independently of intermanual conflict. Normally, the right and left cerebral hemispheres may be complementarily modifying automated whole body actions in order to adapt behaviour to changes of the environment as well as to the intention. Partial callosal disconnection without significant cortical involvement would exaggerate the disparity between the role of each hemisphere through the reorganisation of neural systems after callosal damage. Such double, often contrary, behavioural tendencies may sometimes simultaneously enter the patient's awareness.

(F Neurol Neurosurg Psychiatry 2001;71:462-471)

Keywords: corpus callosum; diagonistic dyspraxia; conflict; intention
Diagonistic dyspraxia is a symptom sometimes seen in patients with callosal damage, in which there is apparent conflict between the desired action and the actually performed act. ${ }^{1}$ Intermanual conflict is also a symptom of the callosal syndrome, in which one hand is acting at cross purposes to the other. ${ }^{2}$ Although these two terms are often used synonymously, Akelaitis, ${ }^{1}$ who first reported diagonistic dyspraxia in two patients, not only noted intermanual conflict, but also peculiar behaviour that could be described as a conflict of intentions. For example, his patient 1 "would want to get up from a sitting position and would succeed in raising herself partly, only to have a sudden desire to sit down again which she would proceed to do." He also noted that "frequently she would start to a destination such as a window, in order to open it, but eventually would find herself going towards the door in the opposite direction." Therefore, the original concept of diagonistic dyspraxia was not confined to abnormalities of hand movements, and intermanual conflict should actually be regarded as one fragment of diagonistic dyspraxia. We encountered three patients with callosal lesions who sometimes could not perform whole body actions as they intended because another intention emerged in competition with the original one. This symptom became manifest during the resolution of intermanual conflict in one patient, occurred in the absence of intermanual conflict in another, and developed during recovery from compulsive manipulation of tools and groping with the right hand in the third patient. It may represent another manifestation of diagonistic dyspraxia, which can occur independently. A few similar cases have been reported previously, ${ }^{3}$ but no specific term has yet been coined for this symptom, so we tentatively name it "conflict of intentions" If conflict of intentions represents part of the callosal disconnection syndrome, how can a callosal symptom manifest as a disturbance of whole body action rather than being confined to one half of the body? Furthermore, there have been many studies on callosal disconnection, so why has this symptom escaped attention previously? We attempt to answer these questions by describing the characteristics of conflict of intentions and discussing the possible mechanism.

\section{Case reports}

CASE 1

The patient was a 41 year old, right handed, male construction worker with senior high school education. He abruptly became aware of 
stammering and abnormal behaviour such as the following. When driving a car, he selected reverse gear with his left hand, although he intended to move forward. Also, when he intended to turn right, his left hand tried to turn the steering wheel instead, after which he panicked and applied the brakes. When he was at home, he opened a sliding door with his right hand and then closed it with his left hand immediately afterwards so that he could not go through the doorway. This action was repeated again and again until he eventually called his wife to help him. Thirty nine days later, the patient was referred for detailed assessment.

\section{Neurological findings}

The patient was alert and well oriented. There were no significant cranial nerve abnormalities except for mild high frequency hearing loss in both ears. His muscle strength and deep tendon reflexes were normal and symmetric, and no pathological reflexes were elicited. Barre's sign was absent in the upper and lower limbs. There was no motor ataxia, but bilateral arm movements were desynchronised in the pronation-supination diadochokinesis test. Perception of pain, temperature, and touch were almost normal, except that pain was felt slightly stronger in the right limbs and touch slightly stronger on the left. Vibration, position sense, and two point discrimination were intact. Cerebral angiography disclosed severe stenosis and delayed flow in the common trunk of the bilateral callosal branches of the anterior cerebral arteries.

\section{Magnetic resonance imaging}

Brain MRI (fig 1) demonstrated an infarct of the corpus callosum that involved the genu, the whole length of the body, and a small upper left part of the splenium, although there was no evidence of cortical damage, including the cingulate gyri and supplementary motor areas.
Neuropsychological findings

Speech was stuttering, but the patient did not show any evidence of aphasia, agnosia, or apraxia apart from some interhemispheric disconnection signs. $\mathrm{He}$ had constructional apraxia in the right hand. He showed ideomotor apraxia in the bilateral hemifaces, the left hand, and the left leg, which were worse on the oral commands and considerably improved on imitations. He also showed agraphia in the left hand, and defective cross replication of hand postures. He exhibited auditory and tactile extinction on the left side when a verbal response was required, although he performed perfectly when responding with raising the hand ipsilateral to the stimulus. (The details of these signs, designated as apparent extinction, were previously reported by Nishikawa et al. ${ }^{5}$ ) The patient also showed left ear suppression on the verbal dichotic listening test by the method of Tanabe et $a l .{ }^{6}$ (The same method was employed in patients 2 and 3.) There was normal naming of words, colours, and the pictures of objects in the left visual field on the tachistoscopic presentation test by the method of Okuda et al (The same method was employed in patients 2 and 3.), as well as normal tactile recognition of objects and of letters drawn on the left hand. Visuomotor ataxia was absent, although he occasionally had difficulty in initiating motion of the left hand to grasp targets in the right (and rarely left) visual field as well as mirror movement of the left hand reflecting the motions of the right hand. Forced grasping, visual groping, and compulsive manipulation of tools were not noted. According to the WAIS-R, his total IQ was 85 , with a verbal IQ of 91 and a performance IQ of 81 .

\section{Clinical course and conflict of intentions}

The patient was followed up for 2 years and 3 months after the onset of his illness. His stuttering gradually subsided, and intermanual conflict almost disappeared within about 2

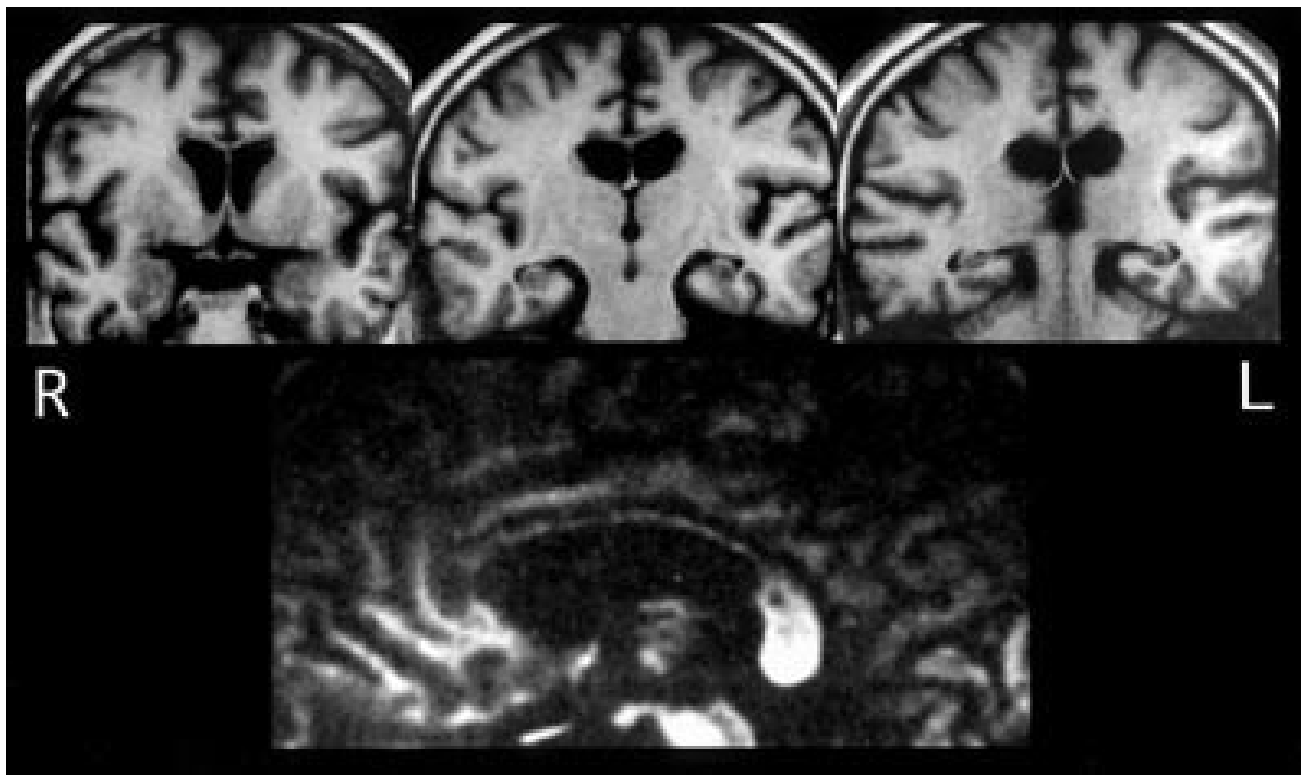

Figure 1 T1 weighted MRI of patient 1 (upper three images, coronal; lower image, midsagittal). 
months. However, other abnormal behaviour gradually became evident from 8 weeks after the onset. The patient reported that he often stopped suddenly when walking along a corridor or ascending the stairs and remained motionless for 10 to 20 minutes. He stated that "I froze while ascending the stairs because a wish to descend came into my mind". On such occasions, he had to call his wife and ask her to assist him to go upstairs. Also, the attending doctor noticed the patient stepping back and forth in the hospital corridor with a washbowl in his hand. When asked what he was doing, he remarked that "I wanted to take a bath and go to the toilet at the same time, and could not choose one of them, so I went to the toilet while carrying the washbowl". The patient could change the hand holding the washbowl from right to left when told to do so. However, he said that "I cannot make myself go to the toilet after putting the washbowl down". He often complained that when he wanted to do something, a competing desire to do something else occurred without any reason, and it took some time before he could perform the intended action. The patient was aware of his illness and repeatedly remarked, "I am afraid that I am insane". Although he showed anxiety and irritation about his symptoms, he neither had "made experiences" (Schneider's gemachtes Erlebnis) nor delusions, and there was no other evidence of psychosis. The symptoms persisted during the follow up period. However, such symptoms did not necessarily develop during every behaviour and had no serious effect on his basic activities of daily living either at home or in the hospital, although the patient could not return to work. Nor did he show any significant conflict when performing tests under the instructions of examiners, except for occasional hesitation in initiating motion of the left hand.
CASE 2

The patient was a 50 year old, right handed, male maintenance worker with senior high school education. He suddenly began to stutter and developed a decrease of clear perception of the presence of his right upper and lower limbs. Two days later, he was referred for assessment.

\section{Neurological findings}

The patient was alert and well oriented. There were no abnormalities of the cranial nerves. His muscle strength and tendon reflexes were normal and symmetric, and no pathological reflexes were elicited. Barre's sign was absent. There was no motor ataxia, but bilateral arm movements were desynchronised in the pronation-supination diadochokinesis test. $\mathrm{He}$ stated that touch sensation was weaker on the right and was easily lost when the stimulus was out of sight, although no right-left difference was seen in the response to a light touch stimulus. His perception of pain, temperature, vibration, joint position, and two point discrimination was judged as intact on the basis of a standard sensory examination.

\section{Magnetic resonance imaging}

On day 4 after the onset, MRI (fig 2) disclosed an oedematous infarct in the left posterior half of the body of the corpus callosum. Several lacunae were also noted in the subcortical white matter. However, there was no noticeable cortical damage, including the cingulate gyri and supplementary motor areas.

\section{Neuropsychological findings}

The patient's speech was stuttering, but he did not show any symptoms of aphasia. Nor did he exhibit any agnosia or apraxia, apart from some features of interhemispheric disconnection syndrome. He showed mild constructional apraxia with the right hand. There was also a localisation deficit in the verbal response to

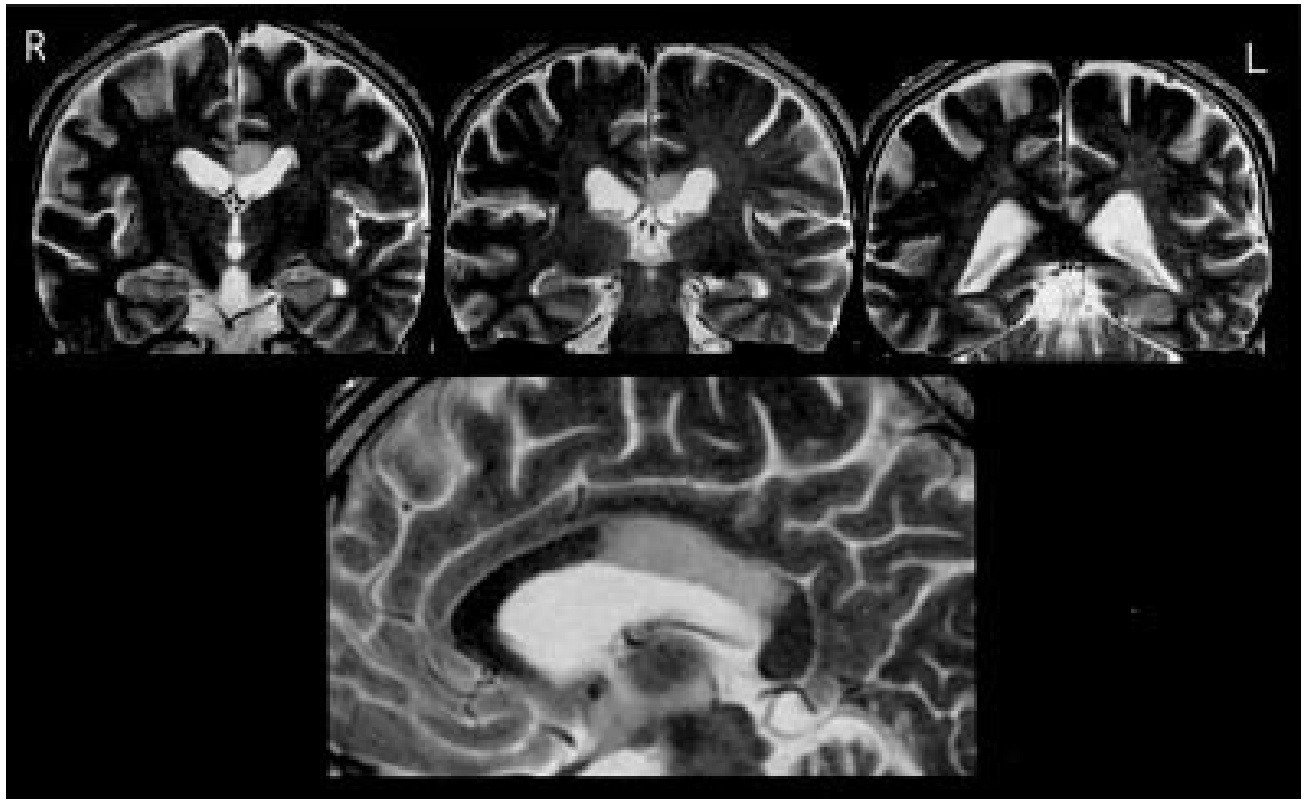

Figure 2 T2 weighted MRI of patient 2 (upper three images, coronal; lower image, midsagittal). 
tactile stimulation of the left fingers (the corresponding motor response was normal), defective cross replication of hand postures, and auditory suppression of the left ear in the verbal dichotic listening test. However, he showed neither ideomotor apraxia of the face, the left hand, or the left leg, nor agraphia of the left hand. He also exhibited no visual, auditory, or tactile extinction of either verbal or manual responses. There was normal visual naming of letters and colours in the left visual field in the tachistoscopic presentation test, as well as normal tactile recognition of objects and letters by the left hand. Visuomotor ataxia, forced grasping, visual groping, compulsive manipulation of tools, and intermanual conflict were absent. In bilateral simultaneous stimulation tests of hand position, touch localisation, and verbal dichotic listening, the patient constantly stated that he was not confident about perceptions on the right side, where he actually showed correct responses, but he did not suspect any problems on the left side where misrecognition actually occurred. According to the WAIS-R, his total IQ was 75 , with a verbal IQ of 77 and a performance IQ of 79 .

\section{Clinical course and conflict of intentions}

The patient was followed up for 1 year and 3 months after the onset of his illness. His stuttering and complaints about vague sensation on the right persisted throughout this period. From about 4 weeks after the onset, the patient began to complain of certain abnormal experiences. He was often seen standing or sitting on a sofa aimlessly in the corridor or the lobby for a long time. When asked what he was doing, he reported his experiences such as "I came to the lobby because I wanted to smoke, but another vague desire occurred and prevented me from smoking. I returned to my room and tried to start from the beginning, but my intention to smoke was again disturbed by another desire." He also stated that "The more I want to move, the more I become frozen." However, when he was encouraged to pursue his original intention, he could perform the action. After he was discharged and returned to work, he reported the following experiences. He wanted to descend a stepladder after finishing some wiring work, but he remained stuck at the top of the ladder for many minutes. He stated that two contrary desires, to descend and not descend, occurred in his mind at the same time and caused conflict, so that he had to choose which course to follow on each occasion. He said that "I experience conflict while I am thinking about doing something and not when I do something without thinking." $\mathrm{He}$ reported that such symptoms were especially common when writing or reading at work. However, the symptoms did not necessarily affect every behaviour and had no serious impact on his basic daily life. He rarely showed any remarkable conflict under test conditions. Although the patient was strongly concerned about his illness and showed anxiety and irritation, there was no other evidence to suggest psychosis such as made experiences or delusions.
CASE 3

The patient was a 23 year old, right handed, restaurant waitress with junior high school education. She had a history of school phobia from the 1 st to 3 rd year of junior high school. She presented at our hospital with headache and vomiting, and was diagnosed as having a brain tumour. She underwent subtotal resection of the tumour in two steps with the first operation via the transcallosal and the second via parietal transcortical approaches. Her tumour was histologically diagnosed as a central neurocytoma. Various symptoms were seen for 2 or 3 weeks after the second operation. Her right hand moved involuntarily to push the call button or grasp the bed sheet and she had to arrest the motion with her left hand. Also, while she was lying in bed, the right hand floated and moved purposelessly. She was discharged after the involuntary movements of the right hand had largely subsided. However, shortly afterwards, various behavioural abnormalities occurred and she was referred for detailed assessment.

\section{Neurological findings}

The patient was alert and well oriented. There were no abnormalities of the cranial nerves. Her muscle strength and tendon reflexes were normal and symmetric, and no pathological reflexes were elicited. Barre's sign was absent. There was no motor ataxia, and bilateral arm movements were synchronous in the pronation-supination test. Perception of pain, temperature, touch, vibration, joint position, and two point discrimination were intact.

\section{Magnetic resonance imaging}

Brain MRI (fig 3) disclosed the incision site of the first operation in the anterior part of the body of the corpus callosum as well as the residual tumour extending into the ventricle. There was also the surgical trace of the second operation in the left parietal cortical and subcortical areas involving callosal white matter of the caudal part of the body and the rostral part of the splenium. Except for these surgical sequelae, there was no other noticeable damage to the bilateral medial cortices, including the cingulate gyri and supplementary motor areas.

\section{Neuropsychological findings}

The patient had no speech disturbance and showed no features of aphasia, although there was a delay in word finding and difficulty in calculating three numbers written down on paper. She had no symptoms of agnosia or apraxia, apart from certain interhemispheric disconnection signs. There were deficits in tactile naming of objects and letters drawn on the left hand, defective cross replication of hand postures, and left ear suppression in the verbal dichotic listening test. However, there was neither constructional apraxia in the right hand nor agraphia in the left hand. Nor did she show ideomotor apraxia in the face or the left hand or foot. She showed no visual, auditory, or tactile extinction of either verbal or manual responses. She exhibited normal visual naming 


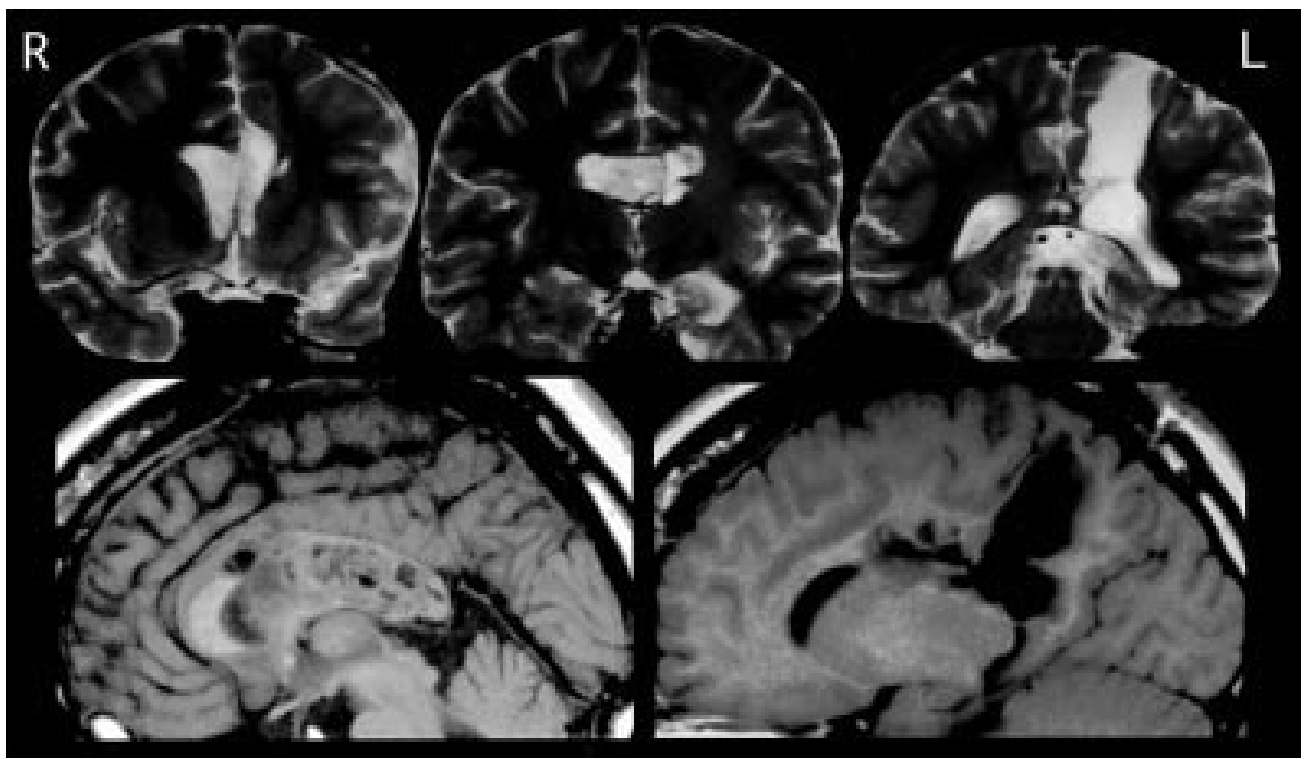

Figure 3 MRI of patient 3 (upper three images, T2 weighted, coronal; lower two images, T2 weighted, midsagittal and 10 mm left sagittal).

of figures, letters, and colours presented to the left visual field by tachistoscope. Visuomotor ataxia was absent. Forced grasping was not elicited. Visual groping, compulsive manipulation of tools, and purposeless spontaneous movement of the right hand, which had occurred in the early postoperative period, were no longer seen. According to the WAIS-R, her total IQ was 62, with a verbal IQ of 77 and a performance IQ of 54 .

Clinical course and conflict of intentions

From about 2 months after the second operation, certain symptoms were noted. When she picked up a cup with the right hand to drink tea, she would become frozen with the cup held aloft for many minutes until her mother moved her hand. When choosing a dress to go out, she would remain sitting in front of several items of clothing for hours. On such occasions, she was alert and could reply to others. She commented on her own experience during these immobile states as follows: "At first, a desire to do something comes into my mind, but it disappears as soon as I begin to try it, and my mind remains blank so I am unable to do anything." However, she always gave evasive answers to questions as to whether she was aware of multiple intentions. On other occasions, she uttered words with the opposite meaning to that intended. For instance, when she wanted to praise the outfit of a friend by saying "It becomes you very well", she actually said, "It is no good." Also, she said that "I dislike that food" when she wanted to say "I like it". She was able to apologise immediately after making such inappropriate comments. Although not all of her behaviour was affected by these abnormalities, problems were frequent and she needed her mother's full time assistance for several months. She remarked that "I wasn't so upset when my right hand was moving by itself, but I became more confused and irritated after my right hand calmed down." Her symptoms gradually abated. At about 10 months after the onset, she still experienced freezing during daily activities, although she said that "before, I had to wait for 30 minutes or 1 hour before I could move, but now I can do so after 2 or 3 minutes." Throughout the course, she was conscious of her illness and showed no evidence of made experiences or delusions. She usually responded rapidly during testing, but occasionally did not respond to a request (for example, to draw her house) until she was urged by the examiner.

\section{Discussion}

The three cases reported here suggest that a peculiar whole body alteration of behaviour can occur in certain patients with partial callosal disconnection, which we have named "conflict of intentions". Even though this symptom is not confined to one side of the body, we consider that it represents a part of the callosal disconnection syndrome. In the subsequent discussion, we clarify the characteristics of this symptom and attempt to explain the underlying mechanism through the dynamic interaction of three processes involved in human behaviour (responsive, intentional, and automatic processes) and their respective main neural substrates (the right cerebral hemisphere, the left cerebral hemisphere, and lower neural systems).

CLINICAL FEATURES OF CONFLICT OF INTENTIONS In table 1 , the findings on our three patients are listed together with the findings obtained for four patients with similar symptoms reported by other authors. These are patients 1 and 2 described by Akelaitis, ${ }^{1}$ a patient described by Fukui et $a l^{3}$ and a patient described by Chan et al. ${ }^{4}$ The manifestations of Akelaitis' patient 1 were mentioned above. His patient 2 had attacks of immobility or began to walk in an unintended direction and was unable to correct this action. This patient also performed repetitive actions such as dressing and undressing. For example, although wishing to get his 
Table 1 Summary of reported cases of presumed "conflict of intentions"

\begin{tabular}{|c|c|c|c|c|c|c|c|c|c|c|c|c|c|}
\hline \multirow[b]{2}{*}{ Authors } & \multirow[b]{2}{*}{ Lesion site } & \multirow{2}{*}{$\begin{array}{l}\text { Latency } \\
\text { from } \\
\text { callosal } \\
\text { damage }\end{array}$} & \multicolumn{4}{|c|}{ Involuntary hand movement } & \multicolumn{5}{|c|}{ Main callosal disconnection sign * } & \multirow{2}{*}{$\begin{array}{l}\text { Awareness } \\
\text {-of } \\
\text { multiple } \\
\text { intentions }\end{array}$} & \multirow[b]{2}{*}{ Stutter } \\
\hline & & & Grasp & Groping & $C M T$ & $I M C$ & Aprax & Agraph & $\begin{array}{l}\text { Tact } \\
\text { anom }\end{array}$ & $\begin{array}{l}\text { Aud } \\
\text { suppress }\end{array}$ & Alex & & \\
\hline \multicolumn{14}{|l|}{ Akelaitis $^{1}$} \\
\hline Case 1 & Post 1/2 GCC, BCC (operation) & $\begin{array}{l}\text { A little } \\
\text { more than } \\
32 \text { days }\end{array}$ & - & - & - & + & $-?$ & $-?$ & $-?$ & ND & ND & $+?$ & Slurring \\
\hline Case 2 & Entire CC (operation) & 36 days & ND & ND & - & $+?$ & $-?$ & $-?$ & $-?$ & ND & ND & $-?$ & - \\
\hline Fukui $e t a l^{3}$ & $\begin{array}{l}\text { GCC, ant } 1 / 2 \text { BCC, white matter } \\
\text { underlying bilateral ACG }(\mathrm{CT})\end{array}$ & 1 month & - & - & - & + & + & - & - & ND & - & $-?$ & - \\
\hline Chan $e t a l^{4}$ & $\begin{array}{l}\text { GCC, BCC, ICC, ACG, right med } \\
\text { prefrontal cortex (MRI) }\end{array}$ & 1 month & + & + & - & + & + & - & - & ND & ND & $-?$ & + \\
\hline \multicolumn{14}{|c|}{ Present report: } \\
\hline Case 1 & GCC, BCC, ant SCC (MRI) & 8 weeks & - & - & - & \pm & + & + & - & + & - & + & + \\
\hline Case 2 & Post $1 / 2$ BCC (MRI) & 4 weeks & - & - & - & - & - & - & - & + & - & + & + \\
\hline Case 3 & $\begin{array}{l}\text { Ant BCC, caudal BCC, rostral SCC, } \\
\text { left parietal lobe (MRI) }\end{array}$ & 2 months & - & \pm & \pm & - & - & - & + & + & - & - & - \\
\hline
\end{tabular}

$\mathrm{CC}=$ Corpus callosum; $\mathrm{GCC}=$ genu corpus callosum; $\mathrm{BCC}=$ body corpus callosum; $\mathrm{ICC}=$ isthmus corpus callosum; $\mathrm{SCC}=$ splenium corpus callosum; $\mathrm{ACG}=$ anterior cingulate gyrus; ant=anterior; post=posterior; med=medial; CMT=compulsive manipulation of tools; IMC=intermanual conflict from diagonistic dyspraxia; aprax =apraxia; agraph=agraphia; tact anom=tactile anomia; aud suppress=auditory suppression elicited by dichotic listening test; Alex=hemialexia elicited by tachistoscopic presentation test; +=present; $-=$ absent; $\pm=$ turned from present to absent with appearence of "conflict of intentions"; ND=no description; ?=presumed by contexts.

^These signs are confined to the left unilateral body.

clothes out of the closet, the patient could not will himself to do so, but instead made several trips passing through the closet room. The patient reported on by Fukui et al would enter the bathroom and wash his face when he passed it, or re-enter the toilet straight after leaving it, opening the door with either his right or left hand, even though he did not want to do so. The patient reported on by Chan et al had attacks of immobility and also went to unintended places. The manifestations actually appeared as abnormal whole body behaviour, although Chan et al explained them by saying that the left leg would not cooperate with the right leg. With respect to such interpedal conflict, three other patients have been reported on, by Levin et al, ${ }^{8}$ Banks et $a l,{ }^{9}$ and Della Sala et al. ${ }^{10}$ However, these patients were not included in table 1 as the abnormalities were reported to be confined to the left side.

The clinical features of conflict of intentions in these seven patients can be summarised as follows.

(1) The patients all had damage to at least half of the body of the corpus callosum in the absence of significant cortical lesions, except for one patient. Akelaitis' patients underwent callosal transection, with the body and the posterior half of the genu being cut in patient 1 and total callosotomy in patient 2 . The patient of Fukui et al had callosal damage secondary to the rupture of an aneurysm. The lesion extended from the genu to the anterior half of the callosal body and involved the surrounding subcortical white matter, but no cortical damage was detected by CT. The patient of Chan et $a l$ is the exception, because MRI showed lesions caused by at least two episodes of infarction, involving not only the corpus callosum from the genu to the isthmus but also the right anterior cingulate gyrus, supplementary motor area, and medial prefrontal cortex. However, the lesions in the right medial frontal cortex seemed to be patchy, by contrast with the much more definite changes of the corpus callosum. Our patients 1 and 2 had callosal lesions caused by infarcts, but MRI failed to detect any cortical lesions. Although such lesions may be considered very rare, Watson et $a l^{11}$ have also reported a case of callosal infarction caused by haemorrhage induced spasm with no evidence of cortical involvement, supporting the fact that these infarcts can sometimes occur. In our patient 3, the lesions were two incision sites for tumour resection, so that cortical involvement was relatively minor and the medial cortex was unaffected. It should also be noted that the callosal damage was partial in all these patients, except for patient 2 of Akelaitis, with total callosotomy. The lesion common to these patients involved the posterior part of the callosal body, except in the patient of Fukui et al. However, as suggested by Tanaka et $a l,{ }^{12}$ his lesion might have been found to extend more posteriorly if MRI had been performed instead of CT.

(2) Conflict of intentions occurs several weeks after callosal damage. According to Akelaitis, diagonistic dyspraxia developed 1 or 2 months postoperatively in both patients. Fukui et al likewise described diagonistic dyspraxia appearing about 1 month after the aneurysm rupture in their patient. In these patients it is not clear whether or not there was a difference in the latency of intermanual conflict and conflict of intentions. The report of Chan et al suggests that intermanual conflict developed from 2 weeks and conflict of intentions appeared from 1 month after the callosal damage. In our patient 1 , intermanual conflict developed immediately after callosal infarction and gradually resolved, whereas conflict of intentions arose around 8 weeks after infarction. In our patient 2, conflict of intentions developed about 4 weeks after callosal infarction. In patient 3, it became manifest with the regression of groping and compulsive manipulation of tools by the right hand about 2 months postoperatively.

(3) Conflict of intentions occurs during spontaneous, but not well automated, actions. In test conditions, none of our three patients showed any marked conflict in general behaviour, although patient 1 occasionally had difficulty in initiating motion with the left hand and patient 3 showed some unresponsiveness to the 
examiner's instruction. When the patients encountered conflict in daily life, commands by other persons were also effective in resolving it. Thus, this behavioural abnormality mainly occurred during self initiated actions. However, conflict of intentions did not always occur during spontaneous activities. According to Akelaitis' report, the symptom was not seen while his patient 1 was writing or doing crossword puzzles, at which she was very adept, nor in his patient 2 during eating, drinking, smoking, or playing cards. Likewise, only some daily activities were affected in our patients. Our patient 2 reported that he had problems not when doing something without thinking, but when performing actions that required thinking. Thus, conflict of intentions seems to be unlikely to appear during well automated activities, but instead occurs during intentional activities. It may also be that such intentional activities are induced by unexpected environmental or physiological changes, as suggested by the fact that cold weather triggered the indecisive behaviour of Akelaitis' patient 2 , and a desire to go to the toilet caused actions dissociated from volition in the patients of Fukui et al, Chan et al, and our patient 1. Even if conflict of intentions occurred during simple activities such as walking or climbing stairs, its manifestation probably depends on how purposefully the patients were acting then.

(4) The objective behavioural abnormalities encompassed by conflict of intentions are interruption of actions, repetition of actions, an inability or a marked delay in initiating actions, performance of inappropriate actions with inability to correct them, and performing mixed actions (for example, going to the toilet holding a wash bowl). Unless the evidence of organic lesion and other neuropsychological findings are obtained, it could be difficult to discriminate such features of conflict of intentions from certain symptoms of mental disorders such as blocking, inhibition, compulsive repetition, or stereotypy, or even from certain actions of healthy people.

Subjective experiences of patients with conflict of intentions

In the presumed cases of conflict of intentions, all the patients seemed to be conscious of their own abnormalities and not a little embarrassed by them. However, there may be different stages in patients' awareness of the multiplicity of their own intentions. Akelaitis briefly reported that his patient 1 , while wanting to get up from a sitting position, developed a sudden desire to sit down. His patient 2 had been unaware of his new desire to get a jacket until he made two trips outside in the cold. For the patients of Fukui et al and Chan et al there is no information about this issue. Our patients 1 and 2 spontaneously stated that they were simultaneously aware of multiple (presumably two) desires in their own minds that were more or less contradictory, whereas patient 3 could not give a clear answer about the existence of multiple desires and instead reported that her original intention tended to disappear very easily.
Based on the descriptions provided by our patients 1 and 2, it also seems that there are various relations between multiple desires. One is that an obviously opposite desire occurred during pursuit of the original intention, as seen in the patient who developed a sudden desire to descend while ascending the stairs. The second is that the original intention was followed by the onset of an alternative but unclear desire, as represented by the patient who wanted to smoke and also wanted to do something different. The third involves simultaneous occurrence of multiple concrete desires to perform different actions that interfere with each other, as seen in the patient who wanted not only to take a bath but also wanted to go to the toilet at the same time. Such various relations between multiple desires may account for the wide range of behaviour in this symptom.

\section{Relation between conflict of intentions and other} symptoms

The alien hand and the anarchic hand are symptoms manifested by involuntary actions only in one hand as well as intermanual conflict, so that conflict of intentions is distinguished without difficulty from these symptoms. However, the concepts and terms of these symptoms are somewhat complicated. Especially concerning the alien hand, various types of abnormalities in one hand have been reported under this term, as several reviewers indicated from their various viewpoints..$^{10}{ }^{12-15}$ This may be attributable to Bogen's definition of the alien hand. ${ }^{2} \mathrm{He}$ expanded the concept of la main étrangère by Brion and Jedynak, ${ }^{16}$ which originally meant only a sign that patients with callosal damage lose the feeling of belonging of their own left hands when they are out of sight. Bogen then redefined this concept under the term, the alien hand, as a motor behavioural symptom by describing "a circumstance in which one of the patient's hands, usually the left hand in the right handed patients, behaves in a way which the patient finds 'foreign', 'alien' or at least 'uncooperative'". Such an indefinite description about alienness seems to have left room for this term to include various involuntary hand actions whether with or without any apparent somatognostic problem. In contrast, the anarchic hand is the more strictly defined to mean the involuntary hand action without cognitive deficit of the ownership of the affected hand. Apart from the terminological problems, the most important and controversial issues about these symptoms may be whether or not callosal damage alone can produce involuntary hand action without any involvement of the mesial frontal cortex, and also whether the manifestations, if there is any, differ in nature from those resulting from frontal lobe lesions. Considering the findings of previous reports and our experience, we can indicate that at least some patients with a lesion limited to the corpus callosum exhibit involuntary action in one (usually the left) hand, but the manifestation is actually transitory. ${ }^{10}{ }^{12}$ Moreover, if such involuntary action due to a callosal lesion appears in the left hand, it seems to be concomitantly elicited by the patient's 
intentional action with the right hand, whereas the involuntary actions resulting from the frontal lesion in either the right or left hand would appear as a direct response to the external stimuli.

Another symptom which needs to be differentiated from conflict of intentions is utilisation behaviour (or environmental dependency syndrome in a wide sense), which was originally proposed by Lhermitte. ${ }^{118}$ This is defined as spontaneous occurrence of complex actions, performed with the patient's whole body, according to an appropriate motor programme, which, however, are inappropriate within the context and which are triggered by external stimuli. Although this symptom is similar to conflict of intentions in some respects, Lhermitte et al indicated that one of its determining features is loss of self criticism in the patients. ${ }^{19}$ They are characteristically indifferent to their abnormal behaviour or show a tendency to justify their improper behaviour. On the contrary, the patients with conflict of intentions are not only aware of the inappropriateness of their own actions but also very critical about these actions, so that their behaviour is also characterised by marked hesitations.

\section{Mechanism of conflict of intentions}

The main theories about certain related symptoms provide important clues for discussion of the mechanism underlying conflict of intentions. Della Sala et $a l^{10}$ explained the mechanism of anarchic hand in the following way. Normally, there is equilibrium between the activity of two separate but interactive premotor cortical systems - that is, the mesial system centred on the supplementary motor area that directs intentional movements driven by inner context, and the lateral system centred on the arcuate premotor area, which is responsible for automatic movements in response to external stimuli. If the unilateral supplementary motor area and the corpus callosum are simultaneously damaged, the ipsilateral arcuate premotor area comes to lose restraint and produce anarchic hand in the contralateral side. Tanaka et $a l^{12}$ explained the occurrence of involuntary action of the left hand in diagonistic dyspraxia as follows: a voluntary intention to act with the right hand calls forth neural activation in the right superior parietal lobule as well as in the left. When transcallosal inhibitory control from the left to the right side is disturbed by a lesion within the ventral part of the posterior callosal body, the visuomotor integrative function in the right superior parietal lobule is released to respond to external stimuli, resulting in the emergence of spontaneous left hand action. From these theories, we can draw important concepts which are applicable to the mechanism of conflict of intentions. Normal behaviour is modulated based on dual balances, which are (1) the balance between the lateral responsive movement system and the mesial control system within each hemisphere, and (2) the balance between the two cerebral hemispheres with the left tending to be involved in directing intentional behaviour and the right being involved in responsive behaviour.

Regarding the mechanism of conflict of intentions, the clinical features also provide some clues. This symptom manifests several weeks after callosal damage, and often appears along with the resolution of intermanual conflict or compulsive manipulation of tools. This suggests that it arises during the reorganisation of hemispheric function after callosal disconnection. Holtzman and Gazzaniga ${ }^{20}$ indicated that each hemisphere exhibits an increase of function above that in the intact state after callosal section, because both hemispheres are released from regulation by the contralateral side. Likewise in conflict of intentions, the intrinsic traits of each hemisphere may be independently exaggerated and this will lead to a state of interhemispheric competition, whereas the preserved medial control system prevents involuntary manual responses by maintaining a balance with the lateral premotor system within each hemisphere.

It has been indicated that the right hemisphere is dominant with respect to phasic changes in alertness, orienting, and preparation for actions on the basis of simple reaction time studies on normal subjects ${ }^{21}$ as well as on patients with brain damage. ${ }^{22-24}$ This has also been confirmed in patients with conflict of intentions. ${ }^{45}$ In addition, on the basis of the findings on various elements of hearing acuity in our patient 1 , we indicated in a previous report that the left hemisphere tends to pursue sustained perceptual impressions by contrast with the right hemisphere. ${ }^{25}$ In normal behaviour, it may be that these specialised characteristics of the two hemispheres act complementarily to achieve consistency when pursuing a purpose as well as flexibility when it is necessary to respond to environmental changes: information from both hemispheres would be integrated to dismiss either of the alternatives or to set up a new intention by combining both of them. In the case of conflict of intentions, because of the lack of interhemispheric harmonisation due to callosal disconnection and, moreover, the traits of each hemisphere being exaggerated, the tendencies of the two hemispheres would remain disintegrated.

Some patients with conflict of intentions were aware of two synchronised but opposing desires. Since the early days of split brain studies, whether or not the human mind and consciousness can be divided has been an important theme, ${ }^{26}{ }^{27}$ although such discussions have tended to become abstract because of the lack of fully established definitions of either mind or consciousness. Gazzaniga ${ }^{28}$ mentioned in a recent review that "consciousness is feelings about specialised capacities we have, such as feelings about objects we see, hear, and feel, and feelings about our capacity to think, to use language, to apprehend faces." And he indicated that the system involved in creating such feelings is confined to the left cerebral hemisphere. However, we consider that, even though only the left hemisphere may have the ability to interpret and report such experiences, it remains possible that the right 
hemisphere can also create such feelings in some cases. And then, if the two hemispheres still communicate to a requisite extent, such feelings of the right hemisphere can be interpreted and verbalised. Involuntary actions limited to one hand are not accompanied by a conscious sense of intention, even if the dominant hand is involved. Thus, a conscious experience of self decided action may be produced only when the hemisphere is functionally well preserved and wholly activated including not only the responsive system but also the inhibitory system. These conditions would be provided by partial callosal disconnection with a lesion in the posterior part of the callosal body without significant involvement of the cerebral cortex.

Why then does conflict of intentions not accompany all behaviour-that is, why are well automated behaviour and responses to instructions usually unaffected? Sperry et $a l^{29}$ indicated that the most remarkable effect of sectioning the cerebral commissures is the apparent lack of change in ordinary behaviour, and suggested that there are factors unifying the body schemata imposed in the two hemispheres under daily conditions. Most ordinary behaviour, which has been developed through years of routine experiences, would proceed automatically as serial sets of whole body action. It probably depends more on the lower neural systems and requires less contribution of the highly specialised functions of the cerebral hemispheres. Then intentional control of actions would become necessary after the occurrence of new ideas or unexpected situations-for example, a change in weather conditions or a desire for urination or evacuation as already mentioned. Thus, conflict of intentions appears when the automatic processes no longer work and it is needed to change the pattern of behaviour. Obeying instructions also does not develop conflict of intentions, probably because most of the actions performed during testing are novel ones for the patients and the detailed instructions leave little room for alternative actions mediated by automatic or responsive processes.

We should also consider the possible contribution of other factors. The patient of Chan et $a l$ and our patients 1 and 2 developed stuttering speech after callosal damage from the earliest stage, and patient 1 of Akelaitis showed slurred speech. This seems to provide evidence for the hypotheses that prosodic information processed in the right hemisphere and linguistic information processed in the left hemisphere is integrated via the corpus callosum, ${ }^{30}$ or that stuttering is the result of competition between the two hemispheres for control of the speech. ${ }^{31}$ However, considering that only a few cases of callosal disconnection associated with stuttering have been previously reported, ${ }^{32} 33$ these patients might have some unique predisposition that led to the division between the two hemispheres of the function relating to production of speech and intention. All of our three patients, and the patients of Fukui et $a l$ and Chan et al were found to have low IQs. Although it is unclear whether these patients were originally endowed with such IQs, it could also reflect a possibility that these patients were especially vulnerable to functional disintegration by callosal disconnection.

Conflict of intentions was described in early studies on callosal disconnection syndrome, but little attention has been paid to this condition. This has probably occurred because the distribution of lesions responsible for this symptom is rare, it only becomes manifest several weeks after the callosal damage, and the nature of this symptom is such that it characterises self initiated behaviour so that it is difficult to directly demonstrate on examination. Thus, if attention was not paid to patients' reports of their experiences, it may often have been overlooked or regarded as arising from other causes such as psychiatric or psychological problems.

1 Akelaitis AJ. Studies on the corpus callosum. Diagonistic dyspraxia in epileptics following partial and complete section of the corpus callosum. Am $\mathcal{F}$ Psychiatry 19441945;101:594-9.

2 Bogen JE. The callosal syndrome. In: Heilman KM, Valenstein E, eds. Clinical Neuropsychology. New York: Oxford University Press, 1979:308-59.

3 Fukui T, Endo K, Sugishita M, et al. A case of callosal damage accompanied with ideomotor apraxia without agraphia, diagonistic apraxia, and intermittent initiation difficulty of left hand. Rinsho Shinkeigaku 1987;27:1073-80.

4 Chan JL, Chen RS, Ng KK. Leg manifestation in alien hand syndrome. F Formos Med Assoc 1996;95:342-6.

5 Nishikawa T, Tanabe H, Okuda J, et al. Extinction in cases of callosal disconnection: "apparent extinction" and some callosal disconnection: "apparent extinction" and some additional findings in dichotic listening test. $\mathcal{F}$ nal ouropsychology (Tokyo) 1988;4:33-46.

nal of Neuropsychology (Tokyo) 1988;4:33-46.
6 Tanabe H, Nishikawa T, Okuda J, et al. Auditory extinction to non-verbal and verbal stimuli. Acta Neurol Scand 1986;73:173-9.

7 Okuda J, Ohigashi Y, Tanabe H, et al. A neuropsychological study on a case with a tumor lesion in the posterior part of the corpus callosum. No To Shinkei (Tokyo) 1984;36:73-80.

8 Levin HS, Goldstein FC, Ghostine SY, et al. Hemispheric disconnection syndrome persisting after anterior cerebral artery aneurysm rupture. Neurosurgery 1987;21:831-8.

9 Banks G, Short P, Martinez AJ, et al. The alien hand syndrome: clinical and postmortem findings. Arch Neurol 1989;46:456-9.

10 Della Sala S, Marchetti C, Spinnler H. The anarchic hand: a front-mesial sign. In: Boller F, Grafman J, eds. Handbook of neuropsychology. Vol 9. Amsterdam: Elsevier, 1994:23355.

11 Watson RT, Heilman KM, Bowers D. Magnetic resonance imaging (MRI, NMR) scan in a case of callosal apraxia and pseudoneglect. Brain 1985;108:535-6.

12 Tanaka Y, Yoshida A, Kawahata N, et al. Diagonistic dyspraxia. Clinical characteristics, responsible lesion and
possible underlying mechanism. Brain 1996;119:859-73.

13 Feinberg TE, Schindler RJ, Flanagan NG, et al. Two alien Feinberg TE, Schindler RJ, Flanagan NG, et al. Two
hand syndromes. [Review]. Neurology 1992;42:19-24

14 Marchetti C, Della Sala S. Disentangling the alien and anarchic hand. Cognitive Neuropsychiatry 1998;3:191-207.

15 Riddoch MJ, Edwards MG, Humphreys GW, et al. Visual affordances direct action: neuropsychological evidence from manual interference. Cognitive Neuropsychology 1998; 15:645-83.

16 Brion S, Jedynak CP. Troubles du transfert interhémisphérique. A propos de trois observations de tumeurs du corpus calleux: le signe de la main étrangère. Revue Neurologique (Paris) 1972;126:257-66.

17 Lhermitte F. "Utilization behaviour" and its relation to lesions of the frontal lobes. Brain 1983;106:237-55.

18 Lhermitte F. Human autonomy and the frontal lobes. Part II: The "environmental dependency syndrome". Ann Neurol 1986;19:335-43.

19 Lhermitte F, Pillon B, Serdaru M. Human autonomy and the frontal lobes. Part I: Imitation and utilization behaviour: a neuropsychological study of 75 patients. Ann Neurol 1986;19:326-34.

20 Holtzman JD, Gazzaniga MS. Enhanced dual task performance following callosal commisurotomy in humans. Neuropsychologia 1985;23:315-21.

21 Heilman KM, Van Den Abell T. Right hemispheric dominance for mediating cerebral activation. Neuropsychologia 1979;17:315-21.

22 De Renzi E, Faglioni P. The comparative efficiency of intelligence and vigilance tests in detecting hemispheric ligence and vigilance tests in detectin
cerebral damage. Cortex 1965;1:410-33.

23 Howes D, Boller F. Simple reaction time: evidence for focal impairment from lesions of the right hemisphere. Brain 1975;98:317-32. 
24 Tartaglione A, Oneto A, Manzino M, et al. Further evidence for focal effect of right hemisphere damage on simple reacfor focal effect of right hemisphere
tion time. Cortex 1987;23:285-92.

25 Nishikawa T, Okuda J, Tabushi K, et al. Hemispheric specialization in elementary auditory perception: a study on a case with callosal infarction. Higher Brain Function Research (Tokyo) 1986;6:1071-82.

26 Sperry RW. Brain bisection and consciousness. In: Eccles J, ed. Brain and conscious experience. New York: SpringerVerlag, 1966:298-313.

27 Ledoux JE, Wilson DH, Gazzaniga MS. A divided mind: observations on conscious properties of the separated hemispheres. Ann Neurol 1977;2:417-21.

28 Gazzaniga MS. Consciousness and the cerebral hemispheres. In: Gazzaniga MS, ed. The cognitive neurosciences. Cambridge: MIT Press, 1994:1391-400.
29 Sperry RW, Gazzaniga MS, Bogen JE. Interhemispheric relationships: the neocortical commisures; syndromes of relationships: the neocortic In Vinken PJ, Bruyn GW, eds. Handbook of clinical neurology. Vol 4. Amsterdam: North-

30 Klouda GV, Robin DA, Graff-Radford NR, et al. The role of callosal connection in speech prosody. Brain Lang 1988;35: $154-71$

31 Orton ST. Reading, writing, and speech problems in children. New York: Norton, 1937:1-215.

32 Endo K, Fukusako Y, Kawamura M, et al. Acquired stuttering associated with callosal infarction. Fapan fournal of Logopedics and Phoniatrics (Tokyo) 1990;31:388-96.

33 Tsumoto T, Nishioka K, Nakakita K, et al. Acquired stuttering associated with callosal infarction: a case report. No Shinkei Geka 1999;27:79-83.

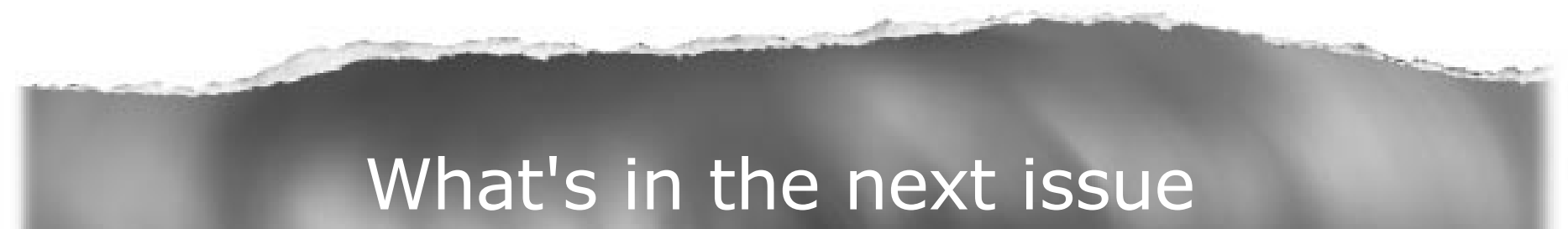

\section{Future content}

See which articles have just been accepted for publication and preview the table of contents for the next issue a month before it is published

www.jnnp.com 